\title{
La industria apícola cerera en el rural de Galicia (1750-1950)
}

\author{
- Damián Copena Rodríguez \\ Universidad de Vigo
}

\section{Introducción}

La apicultura es una actividad orgánica, que forma parte de las sociedades agrarias rurales, en la que se utilizan los recursos que proporciona el ecosistema local. Ciertamente, el ser humano ha aprovechado el incansable trabajo de las abejas desde hace siglos en muchos lugares del planeta, y la sociedad agraria rural gallega no es una excepción. Así, la existencia de una importante superficie forestal y de diversas floraciones melíferas favorecieron la domesticación de la abeja en las áreas rurales con la finalidad de obtener los productos de su trabajo. ${ }^{1}$ Las colmenas fijistas, construidas en el territorio gallego fundamentalmente de corcho o madera, ${ }^{2}$ proporcionaban a sus dueños miel y cera, siendo este último un producto de las abejas muy apreciado al contar con un alto valor de mercado. Efectivamente, los ingresos monetarios de la actividad apícola procedían de la cera, uno de los pocos productos que vendían los campesinos. ${ }^{3}$

Como veremos en el presente artículo, Galicia fue un centro de producción de cera de abeja relevante dentro del territorio peninsular. La existencia de grandes cantidades de colmenas favoreció la aparición, en algunos lugares del interior del territorio rural gallego, de una industria apícola cerera ${ }^{4}$ vin-

1. Pimentel Méndez (1893).

2. Otero Pedrayo (1979), pp. 328-329.

3. Tal como nos indican Lemeunier (2011a), p. 260, y López Álvarez (1994), pp. 130-131.

4. Como veremos más tarde, en contraposición también existe actividad cerera que emplea otros insumos en el proceso productivo sin ninguna vinculación con la apicultura. Por tanto, al estar esta actividad tradicional vinculada directamente con la cera de abeja, podemos definirla como apícola cerera. 
culada con el prensado, el blanqueo y la manufactura de la cera de abeja. Esta actividad económica contaba con elementos y procesos específicos de la cerería de carácter apícola como los lagares y los tendales de cera, infraestructuras adaptadas al producto apícola con el que estaban asociadas. Como se mostrará posteriormente, los componentes físicos específicos vinculados con la industria de cera de abejas perdieron su utilidad con el cambio de insumos en el proceso productivo, que abandonó el producto de las abejas por la estearina y por la parafina, un derivado del petróleo. ${ }^{5}$

La industria apícola cerera, específica del producto vinculado con las abejas, fue una de las actividades económicas relevantes en determinados espacios geográficos rurales del interior de Galicia desde mediados del siglo XVIII hasta principios del xx. Sin embargo, a pesar de la importancia y singularidad con la que contaba localmente esta actividad económica, existe muy poca investigación científica específica sobre ella. Ciertamente, la industria de la cera de abeja ha sido poco estudiada por la historiografía, ${ }^{6}$ siendo escasos los trabajos científicos que abordan los procesos y tecnología utilizada y que analizan la importancia histórica de esta actividad industrial en los territorios rurales.

El presente trabajo tiene como objetivo contribuir a llenar el vacío historiográfico existente en lo relativo al estudio de la industria apícola cerera. Esta cuestión resulta relevante dado el escaso grado de conocimiento científico existente sobre esta actividad económica. Para ello, se realiza el estudio de esta actividad en el territorio gallego en el período histórico que abarca desde mediados del siglo XVIII hasta mediados del XX. En el artículo se contextualiza, dentro del ámbito español, la actividad apícola tradicional en Galicia para abordar, posteriormente, los procesos, los elementos y el análisis geográfico de esta industria. En definitiva, el presente artículo aporta información novedosa sobre una industria apícola cerera que, como veremos a continuación, era relevante en algunos espacios rurales del territorio gallego.

Para poder llevar a cabo este trabajo de investigación ha sido necesario el empleo de diferentes fuentes y metodologías. ${ }^{7}$ Así, prioritariamente, se han utilizado fuentes históricas como el Catastro del Marqués de la Ensenada, el Diccionario Geográfico-Estadístico-Histórico de España y sus posesiones de Ultramar de Pascual Madoz, el Diccionario Geográfico Estadístico de España y Portugal de Sebastián de Miñano, la Estadística Administrativa de la Contribución Industrial, de Comercio y Profesiones, el Anuario General de España Bailly-Baillière-Riera y su antecedente, el Anuario Bailly-Baillière. La información obtenida con estas fuentes se ha complementado a partir de docu-

5. Lemeunier (2011a), p. 268.

6. Ibid. (2011b), p. 17.

7. Gillham (2000). 
mentos históricos de referencia en la materia, principalmente del siglo XIX, como el Arte del cerero, el Manual de fabricante de velas, el Tratado de las abejas y sus labores, etc. Por otra parte, el artículo se nutre de la información existente en la literatura científica con referencias a la materia objeto de estudio. Además, para fortalecer y complementar el conocimiento de los procesos y elementos específicos de la actividad industrial, se ha efectuado un pionero trabajo de campo sobre el patrimonio apícola cerero en el territorio gallego. Para ello, se han utilizado herramientas vinculadas con la investigación participativa ${ }^{8}$ a partir de cuestionarios semiestructurados a los agentes locales identificados con conocimientos en la materia.

El artículo se estructura en una primera sección en la que se realiza una contextualización de la importancia de la apicultura tradicional y su relación con la actividad cerera, destacando la relevancia de la apicultura fijista en el territorio gallego. Posteriormente, se caracterizan los procesos y elementos específicos de la actividad industrial, prensas y lagares de cera y los tendales de cera. A continuación, se analiza la dinámica histórica y geográfica de la industria apícola cerera en Galicia, relativizándola dentro del ámbito español en función de las fases del proceso cerero. El artículo finaliza presentando las principales conclusiones del trabajo de investigación.

\section{Apicultura tradicional y cerería}

La apicultura, una actividad orgánica principalmente recolectora y con escasa inversión en capital y trabajo, ${ }^{9}$ proporcionaba dos importantes productos a los habitantes rurales: la miel y la cera. El primero, dedicado principalmente al autoconsumo, se utilizaba como edulcorante y medicamento. Por su parte, la cera era un producto comercializable y que tenía por sí misma un valor de cambio. ${ }^{10} \mathrm{La}$ apicultura proporcionaba pues rentas para los pequeños propietarios por medio de la venta de la cera, siendo esta actividad más rentable que la venta de miel. ${ }^{11}$

El aprovechamiento de las abejas en España se realizaba en colmenas tradicionales que estaban hechas con materiales muy diversos. ${ }^{12}$ Por el contrario,

8. Cassell y Symon (2004).

9. Lemeunier (2011a), p. 259.

10. López Álvarez (1994), p. 116.

11. Un ejemplo del diferente valor que suministraba cada uno de los dos productos por colmena lo tenemos en los datos del Censo de Frutos y Manufacturas, de Polo y Catalina (1803), que nos indica que, para Galicia, el valor de la cera que proporcionaba una colmena era 1,79 veces superior al que proporcionaba la miel, existiendo un precio unitario 3,5 veces superior para la cera con respecto al otro producto apícola principal.

12. Redondo (1876), p. 61 . 
en el territorio gallego, las colmenas de la apicultura fijista ${ }^{13}$ estaban construidas exclusivamente de corcho y madera. Estas colmenas tradicionales, denominadas covos, trobos y cortizos en gallego, ${ }^{14}$ formaban parte de los aprovechamientos agrarios, siendo una actividad relevante, tal como constatan los siguientes ejemplos: la existencia de una pregunta específica sobre su número en el Catastro de Ensenada ${ }^{15}$ las terribles sanciones establecidas para los robos o quemas de colmenas ${ }^{16}$ o la legislación relativa al derecho de propiedad sobre los enjambres nacidos de la multiplicación natural de las abejas. ${ }^{17}$

Dentro del ámbito español, el territorio gallego, junto a Extremadura y el País Valenciano, ha sido en los dos últimos siglos uno de los principales polos de la apicultura española. ${ }^{18}$ Sin lugar a dudas, esta circunstancia explica, en parte, el desarrollo de la industria apícola cerera en determinadas áreas geográficas de los espacios rurales gallegos. Por otro lado, resulta reseñable el hecho de que el manejo orgánico fijista se mantuviese como predominante hasta mediados de los años ochenta del siglo XX, momento en que se produce la entrada en el noroeste peninsular de la plaga de la varroa (Varroa destructor $).{ }^{19}$ Efectivamente, a pesar de los esfuerzos formadore ${ }^{20} \mathrm{y}$ divulgadores de personas como Benigno Ledo, «el cura de las abejas», ${ }^{21}$ el modelo de apicultura movilista, ${ }^{22}$ más productivo en miel e intensivo en aprovechamiento de las abejas, no ha sido masivo en el territorio gallego hasta hace muy po-

13. Denominada de este modo porque los panales que construyen las abejas no se pueden separar de la colmena.

14. Los covos estaban hechos de troncos vaciados, los trobos de maderas unidas en forma de cajón y los cortizos eran cilindros hechos de la corteza del alcornoque (Quercus suber). Cendón et al. (2011), pp. 4-5.

15. Dentro de las respuestas generales del catastro del marqués de la Ensenada la pregunta número 19 interroga sobre el número de colmenas: si hay colmenas en el término, cuántas y a quién pertenecen.

16. Los delitos de robo e incendio de colmenas cuando el robo es en despoblado cuentan con las siguientes penas: «azotes, corte de orejas y pie, y muerte de saeta, según fuese el valor del hurto». Abarca Castellano (1835), pp. 280-281.

17. Tal como consta en el artículo 612 del Real Decreto de 24 de julio de 1889 por el que se publica el Código Civil: el propietario de un enjambre de abejas tendrá derecho a perseguirlo sobre el fundo ajeno, indemnizando al poseedor de este el daño causado. Si estuviere cercado, necesitará el consentimiento del dueño para penetrar en él. Cuando el propietario no haya perseguido, o cese de perseguir el enjambre dos días consecutivos, podrá el poseedor de la finca ocuparlo o retenerlo.

18. Lemeunier (2011b), p. 38.

19. La entrada de la varroa en España está documentada en el año 1985 por el MAGRAMA (2016), p. 89.

20. Como ocurre en las conclusiones del Primer Congreso de Economía Gallega celebrado en Lugo en 1925 donde, a raíz de la memoria presentada por Benigno Ledo, se acuerda recomendar a los labradores gallegos que adopten el sistema apícola movilista.

21. Benigno Ledo introdujo en el territorio español la primera colmena movilista. Roma Fabrega (1982), p. 46.

22. Las colmenas movilistas, al contrario que las fijistas, cuentan en su interior con unos cuadros móviles de madera sobre los que se sitúan los panales y que pueden ser retirados, lo que permite la colocación en los mismos de cera estampada. 
cas décadas. Los datos que nos suministra el Anuario de Estadística de Espa$\tilde{n} a$ nos indican que el cambio de modelo apícola en Galicia es mucho más lento que en la mayor parte del Estado. Así, en el año 1934 el porcentaje de colmenas movilistas para el conjunto del Estado era del 7,3 \%, siendo en Galicia del 2,6\%. Pocos años después, en 1942, las colmenas movilistas avanzan hasta el 26,7 \% en el Estado y al 15,4 \% en Galicia. Sin embargo, posteriormente este proceso, que continúa en el conjunto del Estado, se detiene en el territorio gallego. Si analizamos las colmenas en el año 1980 podemos observar que el $70,9 \%$ de las del conjunto del Estado son movilistas, mientras que apenas el $26,1 \%$ de las gallegas están vinculadas con la apicultura moderna. Es decir, hasta la década de los ochenta del siglo Xx la apicultura en Galicia era fundamentalmente fijista y solo la entrada del ácaro varroa aceleró el cambio de modelo productivo. Esta cuestión resulta relevante, ya que la productividad cerera de las colmenas fijistas es muy superior a la de las movilistas, al contrario de lo que ocurre con la producción de miel. Lo resume con nitidez el Manual de apicultura escrito expresamente para los apicultores galle$\operatorname{gos}^{23}$ al indicar que el sistema apícola movilista tenía como finalidad la obtención de cantidades más considerables de miel, sacrificando voluntariamente la recolección de la cera. La existencia de un modelo de apicultura orgánico fijista favoreció, por tanto, la producción cerera gallega.

La destacada producción de cera en el territorio gallego aparece recogida en el apéndice de la traducción al castellano del Arte del Cerero, ${ }^{24}$ donde se señala que en Galicia hay «bastante cosecha de cera» y se indica que las zonas donde se produce cera de superior calidad son las tierras contiguas a Portugal, existiendo también producción en la zona de Ourense. Efectivamente, en torno al año 1800 Galicia era uno de los principales espacios geográficos productores de cera de abeja de España. ${ }^{25}$ Un producto que tuvo repercusión incluso más allá de las fronteras ibéricas al participar en la Exposición Universal de París de $1865^{26}$ y que también obtuvo menciones y premios en el ámbito español, tal como consta en la Memoria sobre los productos de la agricultura española, reunidos en la exposición general de $1857 .{ }^{27}$

En lo relativo a las colmenas existentes en el territorio gallego, el Catastro de Ensenada nos indica que, a mediados del siglo XVIII, su número era de 366.339. ${ }^{28}$ Esta cifra resulta realmente espectacular si la comparamos con los datos que nos proporciona el Anuario de Estadística de España desde media-

23. Pimentel (1893), p. 9.

24. Duhame (1777).

25. Lemeunier (2011a), p. 260.

26. Otero Pedrayo (1958), p. 260.

27. Concretamente la participación gallega obtuvo una medalla de bronce por cera amarilla y blanca de la cerería de D. José Cibeira, de O Carballiño (Ourense), y una mención honorífica por la cera amarilla de D. Francisco Barreiro de Forcarei (Pontevedra).

28. González Pérez (1989). 
TABLA 1 - Dinámica del número de colmenas en Galicia y en el conjunto del Estado

\begin{tabular}{|c|c|c|c|c|c|c|c|}
\hline & $\begin{array}{c}1866- \\
1867\end{array}$ & 1888 & 1934 & 1942 & 1948 & 1955 & 1980 \\
\hline A Coruña & 22.123 & 21.288 & 23.655 & 29.678 & 27.534 & 8.903 & 9.080 \\
\hline Lugo & 10.098 & n.d. & 67.530 & 50.000 & 45.168 & 43.559 & 24.705 \\
\hline Ourense & 30.728 & 13.495 & 49.367 & 40.642 & 36.774 & 20.294 & 19.500 \\
\hline Pontevedra & 1.031 & 6.409 & 12.333 & 14.164 & 12.994 & 12.042 & 6.730 \\
\hline Galicia & 63.980 & n. d. & 152.885 & 134.484 & 122.470 & 84.798 & 60.015 \\
\hline Estado & 847.463 & 776.404 & 1.061 .457 & 752.513 & 644.527 & 601.695 & 796.893 \\
\hline
\end{tabular}

Fuente: Anuario de Estadística de España.

dos del siglo XIX, con cifras anuales para las colmenas de Galicia muy dispares, que van desde las 63.980 del año 1866 hasta las 152.885 de 1934. Los datos que nos aporta esta fuente estadística nos indican que las colmenas gallegas representan desde 1934 hasta mediados del siglo XX entre el 14\% y el 19\% del total de las colmenas del Estado, con un número unitario por apicultor más reducido que la media estatal, lo que sugiere una estructura productiva apícola más difusa y ligada al autoconsumo familiar.

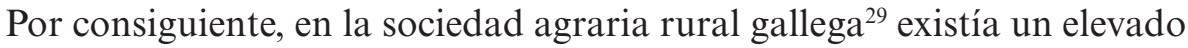
número de colmenas fijistas repartidas por su territorio que los pequeños apicultores utilizaban para conseguir miel y cera, producto este último que vendían en bruto y que les permitía obtener rentas. Este es, sin lugar a dudas, un factor necesario para explicar el desarrollo de la industria apícola cerera en determinados espacios rurales de Galicia.

\section{Procesos y elementos de la industria apícola cerera}

La industria apícola cerera era una actividad relativamente compleja, en la que existían diferentes procesos y elementos específicos. El análisis de la dinámica histórica de esta actividad industrial requiere de un conocimiento previo de las distintas fases que conforman el ciclo productivo completo de la cerería apícola. De este modo, las fases de la cerería apícola, que aparecen reflejadas en la siguiente figura, van a ser analizadas en el presente apartado.

El inicio de la actividad apícola cerera se vincula directamente a las abejas que habitaban las colmenas fijistas. En consecuencia, la obtención de ma-

29. A mediados del siglo XVIII en Galicia apenas un 5\% de la población residía en núcleos urbanos. Saavedra Fernández (2007). 
FIGURA 1 - Principales procesos y elementos del ciclo de la cerería apícola tradicional

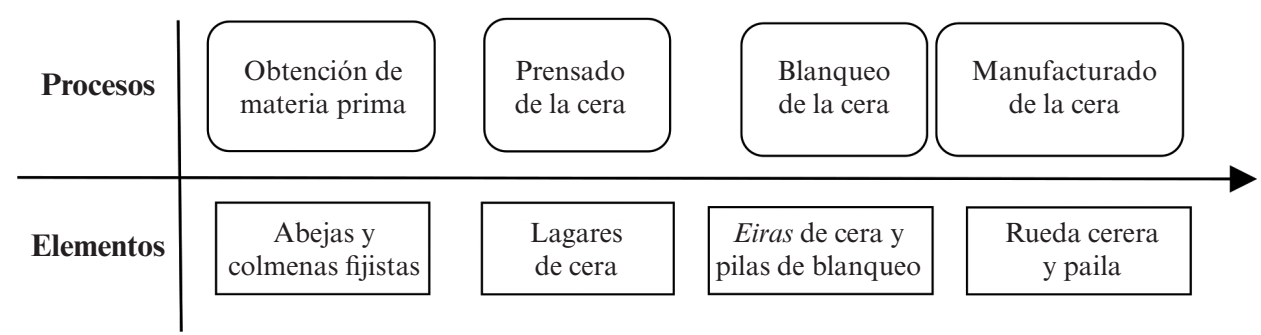

teria prima ${ }^{30}$ se desarrollaba geográficamente con los espacios de mayor producción apícola. Los cereros recorrían estos lugares para comprar a los pequeños apicultores los restos de las colmenas, ${ }^{31}$ después de la castra de la miel, ${ }^{32}$ o la cera ya en forma de borra. ${ }^{33}$ En algunos casos, el proceso de adquisición de materia prima abarcaba importantes extensiones, alcanzando incluso distancias superiores a los cien kilómetros, desde Terra de Montes hasta la zona de Ancares. ${ }^{34}$ Por su parte, los cereros de O Covelo llegaban a hacer acopio del producto de las abejas en O Baixo Miño y la frontera entre Ourense y Portugal. ${ }^{35}$ Durante este proceso los cereros solían ofrecer la prestación de otros servicios, como el de castrador de colmenas o el de capador, con el objetivo de incrementar el acopio de materia prima, ya que podían ser pagados en especies con los restos de las colmenas tras castrar la miel. ${ }^{36}$ Estos cereros ambulantes aprovechaban los viajes para vender directamente en las áreas rurales los productos realizados a partir de cera de abeja que las familias necesitaban para determinadas celebraciones que se sucedían en el calendario litúrgico.

30. Rodríguez Troncoso et al. (2015) señala que la recolección de la miel y la cera se realizaba, en determinados lugares del norte de Galicia, mediante el apicidio, a través del ahogamiento de las abejas, tal como también sucedía, según López Álvarez (1994), en zonas de Asturias, o en el norte de Portugal. Santos Junior (1983).

31. El contenido de las colmenas tradicionales era a veces comercializado en bruto con la miel, cera y restos de insectos mezclados o en semibruto después de la castra de la miel, pero alcanzaba más valor si existía una primera depuración y se vendía en panes o bolos, tal como indican Lemeunier (2011a) y Otero Pedrayo (1979).

32. La castra de la miel consiste en quitar a las colmenas panales con miel, dejando los suficientes para que las abejas puedan mantenerse y fabricar nueva miel.

33. La cera en borra se obtiene en forma de bola, tras un pequeño prensado manual.

34. González Pérez (1989).

35. Cendón et al. (2011), p. 19.

36. Ibid., p. 20. 


\section{El prensado de la cera de abeja: los lagares de cera}

Tras la consecución de la materia prima, la actividad cerera necesitaba realizar su prensado para obtener cera en bloque. Este proceso era muy importante, puesto que permitía purificar la cera, eliminando las impurezas y obteniendo la cera en bruto o cera virgen. ${ }^{37}$ Esta fase del ciclo cerero está tratada en la literatura apícola del siglo XIX. Así, el Manual de Colmeneros ${ }^{38}$ señala que las personas que disponían de pocas colmenas y querían aprovechar la cera de abeja utilizaban pequeños utensilios como prensas manuales. ${ }^{39} \mathrm{Sin}$ embargo, las que se dedicaban a la cerería requerían de infraestructuras para el prensado. Así, aunque la cera se podía purificar utilizando otros sistemas, cuando existían cantidades importantes el mejor método de prensado era usar la prensa o el lagar, dado que la cera se extraía completamente y no mermaba ${ }^{40}$ Es decir, para procesos industriales la tecnología utilizada era las prensas de husillo verticales ${ }^{41}$ o los lagares de prensa de viga, siendo este último, como veremos posteriormente, el elemento de prensado de cera más destacado. Estos lagares cereros se pueden encontrar fundamentalmente en áreas del norte peninsular. Así, han sido estudiados en regiones del norte de España diferentes lagares de cera con prensa de viga ${ }^{42}$ como los de Maranchón (Guadalajara), ${ }^{43}$ Cachorrero (Asturias) o los de Manzanal de Arriba ${ }^{44}$ (Zamora). ${ }^{45}$ Del mismo modo, también se encuentran ejemplos de estos elementos específicos de la cerería apícola en el norte de Portugal, como el lagar de Felgueiras (Torre de Moncorvo) o el de Penafiel. ${ }^{46}$

En Galicia, el trabajo de campo realizado nos permite afirmar que actualmente perviven, cuando menos, seis lagares de cera de prensa de viga en distinto estado de conservación. Tres de ellos son de gran porte y están vinculados con los dos espacios geográficos de la provincia de Pontevedra que, como

37. Cruz García (1989), pp. 5-7.

38. Abarca Castellano (1835).

39. Similares a las que eran usadas en la localidad lucense de Navia de Suarna. López Álvarez (1994), p. 134.

40. Ruiz de la Escalera (1935), p. 86.

41. A día de hoy en Galicia hay ejemplos de prensas de husillo en O Valadouro, A Fonsagrada y en Santa María de O (Muxía), semejantes a las que se pueden encontrar en otros lugares del Estado como Lebrancón (Guadalajara) o Restiello (Asturias). Castellote Herrero (1988); López Álvarez (1994).

42. Castellote Herrero (1988); López Álvarez (1994); Alonso González (1987).

43. Un lagar de cera de Maranchón se encuentra en el Museo Apícola de Azuqueca de Henares (Madrid).

44. En Sagalllos (Manzanal de Arriba-Zamora) se conservan dos lagares de cera de prensa de viga.

45. En Zamora había otro lagar de cera que se halla en la actualidad en el Centro de Interpretación de la Apicultura para la Conservación de la Biodiversidad de Lanjarón (Granada).

46. Santos Junior (1983); Soeiro (2011). 
veremos más adelante, contaron con mayor relevancia en la cerería apícola. ${ }^{47}$ Así, dos de los grandes lagares de cera se encuentran en O Covelo y uno en el ayuntamiento de Forcarei. ${ }^{48}$ Los otros tres lagares, de menor tamaño, están localizados en la provincia de Lugo, concretamente en los ayuntamientos de O Incio, O Valadouro y Sober. Estos importantes elementos patrimoniales de prensado de la cera de abeja, que tenían una titularidad privada, ${ }^{49}$ se parecen en muchos aspectos a los de vino, sidra o aceite, aunque cuentan con unas especificidades propias derivadas de la materia prima que van a prensar. De este modo, los lagares de cera de prensa de viga además de los elementos comunes a otros lagares, como el peso, huso y viga, cuentan con una caldera de cobre donde se hierven los restos de colmenas, un sistema de pilas de piedra para separar la cera del agua y de las impurezas por diferentes densidades ${ }^{50}$ y un conjunto de pilas de enfriamiento, también de piedra, para conseguir la cera en bloque. Para el prensado de los restos de colmenas era necesaria también la utilización de un taco de prensar diseñado específicamente para esta tarea con una serie de agujeros por donde pasaba la cera prensada, y de un elemento filtrante, normalmente serones de esparto, que permitía eliminar las impurezas existentes en la materia prima. El proceso de prensado de la cera en los lagares de prensa de viga posibilitaba la obtención de grandes bloques de cera de abeja amarilla ${ }^{51}$ de unos cincuenta kilogramos ${ }^{52}$ que podían utilizarse en los obradores para manufacturar, ser destinados a la fase de blanqueo o comercializarse directamente en ese estado.

\section{El blanqueo de la cera: los tendales o eiras de cera}

El análisis de la industria apícola cerera nos muestra la existencia de procesos de transformación del producto para la obtención de valor añadido. En este sentido, de manera destacada, se presenta el proceso de blanqueo natu-

47. Los lagares de Forcarei y Covelo, situados dentro de una edificación específica utilizada únicamente para la actividad de prensado, cuentan con grandes vigas que alcanzan entre seis y siete metros de longitud y con unas pilas de separación por diferente densidad hechas de piedra que están inmóviles y enterradas a nivel del suelo.

48. Los lagares de cera de Covelo están en A Lamosa y Paraños (este último conocido como el lagar del tío Bernardos). El de Forcarei está situado en el lugar de A Casanova.

49. El único lagar comunitario del que se tiene constancia es el de Felgueiras, en Torre de Moncorvo, Portugal. Santos Junior (1983).

50. Los lagares gallegos cuentan, en los casos conocidos, con tres pilas de piedra unidas entre sí que posibilitan la separación de la cera por diferentes densidades, ya que flota sobre el agua. Este sistema es distinto al existente en los lagares del norte de Portugal, que solo cuentan con una pila, como se puede comprobar en Santos Junior (1983) y en Soeiro (2011).

51. Tal como señala Clément (2012), la cera de abeja es blanca cuando la producen los insectos en las glándulas cereras, pero se va convirtiendo en amarilla a través de los carotenoides de las flores y el uso, llegando a ser finalmente de color amarillo pardusco.

52. Se puede conocer el manejo de los grandes lagares de cera de prensa de viga gallegos en Cendón et al. (2011). 
ral al que se podía someter la cera amarilla, lo que posibilitaba el incremento de su valor monetario. ${ }^{53} \mathrm{El}$ proceso era relativamente sencillo, dado que se trataba de hacer virutas a partir de los bloques de cera amarilla para exponerla posteriormente al sol y dejar que la acción fotoquímica destruyese las materias colorantes. ${ }^{54}$ Para ello, era necesaria una serie de elementos específicos, principalmente el tendal o eira ${ }^{55}$ y la pila de blanqueo, lo que propiciaba que en los lugares donde se desarrollaba el blanqueo se apostase por la especialización en este ámbito productivo.

Diferentes documentos franceses de los siglos XVIII y XIX explican con detalle el proceso de blanqueo de la cera, señalando que se utilizaban tendederos de madera para colocar los toldos en los que se tendía la cera hecha virutas. ${ }^{56}$ Pero también existían otros métodos de blanqueo como el que se recoge en la traducción española del Arte del Cerero de 1777, donde se indica que en España estos tendales estaban hechos de ladrillos grandes, llamados baldosas. Esta caracterización de estructuras de blanqueo, inmóviles y perdurables, coincide con los elementos que se pueden encontrar actualmente en el noroeste peninsular y, de manera muy destacada, en la zona de O Covelo (Pontevedra). Efectivamente, el trabajo de campo realizado nos muestra que los blanqueadores de cera ${ }^{57}$ gallegos, hechos por lo común de granito, son estructuras rectangulares formadas por grandes losas trabajadas por la cara visible con una leve inclinación que conforman un empedrado perfecto. Estas infraestructuras terminan con un borde hecho en piedra en todo su perímetro que, en la vertiente inclinada, presenta una serie de pequeños desaguaderos para facilitar el escurrido del agua. No se han encontrado elementos de madera como los señalados en los documentos históricos franceses, que, en apariencia, estarían más vinculados con grandes industrias de blanqueo en ámbitos urbanos y no con las pequeñas industrias rurales de blanqueo de la cera. Ciertamente, como veremos más adelante, las principales referencias históricas del blanqueo de la cera de abeja en Galicia aparecen ligadas al mundo rural. En este sentido, cabe constatar que la totalidad de los ocho tendales de cera gallegos localizados en el trabajo de campo se encuentran en el término municipal de O Covelo. Dentro de esta localidad, la parroquia de A Lamosa, que como veremos posteriormente cuenta con referencias históricas específicas de blanqueo de la cera, conserva hoy día seis eiras de cera, siendo la más grande

53. López Álvarez (1994), pp. 127-128.

54. Castellote Herrero (1988) y Cendón et al. (2011), pp. 22-24.

55. Tal como señalan Bas (1983) y Caamaño (2003), las eiras en Galicia se identifican principalmente con la malla tradicional de cereales como el centeno, el trigo o la cebada, que consisten en espacios arquitectónicos que van al aire libre, cubiertas con losas de piedra y que tienen formas diversas.

56. Duhame (1777); Collantes (1864).

57. Los blanqueadores de cera reciben diferentes nombres: tenderos, tendales, eras de la cera... En Galicia se denominan curadoiros o eiras de cera. 
de ciento treinta y dos metros cuadrados, un tamaño realmente considerable. Estas infraestructuras de blanqueo localizadas presentan dos modalidades: por una parte, las de mayor tamaño, que están a ras de suelo, muy similares a las existentes en la localidad zamorana de $\mathrm{Cional}^{58}$ y a las que hacen referencia otros autores ${ }^{59}$ para diferentes lugares del noroeste peninsular. Por otra, las que consisten en tendales de cera que están elevados del suelo mediante pilares de granito. En concreto se han identificado tres tendales de cera elevados y se desconoce la existencia de otros similares fuera del territorio gallego.

Finalmente, el elemento adicional específico necesario para esta actividad de la industria apícola cerera consiste en las pilas de blanqueo. Estas son grandes pilas de piedra de hasta metro y medio de largo que tenían en la parte superior un rodillo de madera. El trabajo de campo ha permitido localizar seis de estas pilas, cinco de las cuales están situadas en O Covelo (tres en A La$\operatorname{mosa}^{60}$ y dos en Paraños) y la restante, en el ayuntamiento de Forcarei.

El proceso de blanqueo consistía en hervir la cera de abeja en una pieza de cobre estañado denominada paila ${ }^{61}$ para verterla, posteriormente, encima del rodillo de la pila de blanqueo, a la que se le ha añadido previamente agua. La cera amarilla líquida entraba en contacto con el agua y se transformaba en hilos o virutas que se trasladaban hasta el tendal de piedra. Allí, tras varios días en los que era preciso realizar tareas de regado para evitar que la cera se pegase en la piedra, ${ }^{62}$ el producto terminaba blanqueándose y se obtenía la cera blanca, denominada popularmente cera «esperma». ${ }^{63}$

\section{Manufacturado de la cera: elaboración de velas y exvotos}

El ciclo de la cerería apícola tradicional terminaba con el proceso de manufacturado de la cera de abeja en el obrador cerero. En este espacio, a partir de los bloques de cera amarilla o blanca, se obtenían los productos finales, fundamentalmente velas y exvotos. En algunas cererías rurales se llegaba a cerrar el ciclo completo desde la obtención de materia prima hasta el manufacturado de la cera de abeja, aunque este proceso final estaba más ligado a espacios urbanos. En este sentido, normalmente la cera de abeja prensada se vendía en las ciudades a las personas que la transformaban en dichos productos. ${ }^{64}$ Sin embargo, también existían pequeñas cererías rurales en espacios

58. Alonso González (1987).

59. Santos Junior (1983); Alonso González (1987).

60. Varias de ellas son propiedad de la familia conocida como Brasileiras.

61. La paila era una pieza de cobre estañado con forma troncocónica muy utilizada en los procesos cereros.

62. Abarca Castellano (1835), p. 251.

63. Copena et al. (2016), p. 246.

64. Lorenzo Fernández (1995), pp. 220-221. 
adaptados para esta actividad en las propias viviendas de los cereros ${ }^{65}$ en los que se manufacturaba esta sustancia apícola para hacer velas y exvotos, utilizando elementos comunes a los existentes en otras zonas de la Península. ${ }^{66}$ Así, existía una rueda cerera hecha en madera, de en torno a un metro de diámetro, desde donde se colgaban las mechas para hacer las velas. ${ }^{67}$ Debajo de ella se colocaba la paila, que servía para hervir la cera. El proceso de fabricación de las velas era totalmente manual y consistía en una sucesión de baños a las mechas con un cazo, una a una, hasta conseguir el grosor adecuado. En este proceso artesanal se utilizaban otras piezas específicas de madera como el bruñidor, con el que se igualaban las velas, y la talladeira, que permitía cortarlas sin partir la mecha. ${ }^{68}$ Estas ruedas cereras más tradicionales dieron paso a otras más modernas, poligonales ${ }^{69}$ que utilizaban el noque. ${ }^{70}$ Estas nuevas ruedas permitían hacer muchas más velas de cera de abeja a la vez, ya que cada lado del polígono contaba con una tabla rectangular donde se podían colocar veinte mechas que, a partir de contrapesos, se podían bañar en el noque de una tacada. Además de las velas, en los obradores cereros la fabricación de exvotos era una actividad extendida. Estas figuras, que no solían ser macizas, estaban vinculadas con ofrendas religiosas ${ }^{71}$ siendo elaboradas a partir de moldes, que podían ser de madera, latón o yeso. ${ }^{72}$

El proceso de manufactura obtenía velas y exvotos que eran muy apreciados y contaban con una importante demanda, principalmente para el ámbito religioso. ${ }^{73}$ Por el contrario, la demanda para consumo laico era reducida, puesto que el elevado precio de la cera de abeja limitaba su uso a la élite social ${ }^{74}$ utilizando la gente del común otros medios de iluminación como las velas de sebo. Esta dependencia del mercado religioso motivó que el progresivo aperturismo a la entrada de otros productos mezclados con la cera en los centros de culto, como la parafina, repercutiese negativamente en la demanda de cera de abeja y en la industria apícola cerera. ${ }^{75}$ Resulta reseñable cons-

65. Cendón et al. (2011), p. 17.

66. El proceso del obrador cerero aparece recogido en Armendáriz Martija (1998), Santos Junior (1983), Castellote Herrero (1988) y Argente Oliver et al. (1992).

67. El trabajo de campo realizado ha permitido encontrar ruedas cereras y pailas en diferentes lugares de la geografía gallega: Covelo, O Incio, Valadouro, Muxía y Forcarei.

68. Cendon et al. (2011); Bellido Blanco (2006).

69. Hay ejemplos de ruedas poligonales en lugares como Forcarei, O Incio o Pontedeume.

70. El noque es un depósito rectangular que permite mantener la cera de abeja u otros insumos en estado líquido. Díaz Maderuelo et al. (1985), pp. 299-300.

71. Fuentes Allende (1994).

72. Cendón et al. (2011), p. 15.

73. La Comisión de Cuestiones Litúrgicas recordaba en 1885 que la cera y el aceite eran las únicas materias permitidas para iluminar los altares, estando prohibido el uso de sustancias más baratas como el sebo. López Álvarez (1994), p. 113.

74. Lemeunier (2011a), p. 261.

75. Resulta necesario señalar que, aunque el destino religioso era el principal, las aplicaciones y usos de esta producción de la abeja eran múltiples. Ledo González (1929), p. 129. 
tatar cómo el importante valor de la cera en comparación con otros insumos sustitutivos motivaba la existencia de falsificaciones en las que el producto apícola se mezclaba con innumerables sustancias que se empleaban para adulterarla,${ }^{76}$ por lo que se difundieron diversos métodos para reconocer los fraudes. ${ }^{77}$

Los obradores cereros, con sus principales elementos y manejos específicos, junto a los lagares de cera y a los tendales de blanqueo, han legado un patrimonio material e inmaterial singular de este oficio vinculado con las abejas, que se conformó gracias a la existencia de una industria apícola cerera vinculada fundamentalmente con espacios rurales concretos, tal como vamos a analizar a continuación.

\section{Geografía y dinámica de la industria apícola cerera en Galicia}

Las actividades industriales vinculadas con la cera de abeja tuvieron repercusión en Galicia, sobre todo en determinados espacios geográficos rurales del interior que se especializaron en ámbitos específicos de la cerería apícola. Efectivamente, el prensado de la cera y su blanqueo son actividades que se desarrollaron en ocasiones en las áreas de influencia de las grandes zonas apícolas del sur de Europa. ${ }^{78}$ Este hecho se cumple claramente en el caso gallego, pues una parte importante de las actividades industriales cereras se desarrollaron en áreas de media montaña. La transformación final de los productos, la manufactura de la cera en bloque, estuvo en determinados momentos más ligada a los centros urbanos y a grandes industrias, aunque también se realizaba de forma muy artesanal en pequeños talleres rurales que eran capaces de cerrar el ciclo de la cerería apícola, comenzando con la obtención de materia prima, pasando por el prensado y el posterior blanqueo de la cera, hasta la transformación y venta final de los productos manufacturados. ${ }^{79}$ Teniendo en cuenta los diferentes procesos del ciclo de la industria apícola cerera, en el presente apartado vamos a proceder a la identificación de los principales espacios geográficos gallegos en donde se desarrollaron cada uno de los ámbitos productivos que caracterizan la industria que utilizaba la cera de abeja.

76. Con fécula de patata, pequeñas cantidades de sebo, yeso, creta, almidón y cera vegetal, la ceresina, la parafina, la estearina y las resinas. Oriol Ronquillo (1853), p. 29; Ledo González (1929), p. 129.

77. Algunos de ellos los podemos encontrar en Collantes (1864); Ledo González (1929) y Oriol Ronquillo (1853).

78. Lemeunier (2011a), p. 264.

79. Copena et al. (2016). 


\section{La industria de prensado de cera}

El período temporal que abarca desde mediados del siglo XVIII hasta mediados del XIX es un momento de esplendor de la actividad cerera, siendo considerado como la última edad de oro de esta industria apícola ${ }^{80}$ debido fundamentalmente a la demanda del clero y la aristocracia. En Galicia a mediados del siglo XVIII la obtención de materia prima y el posterior proceso de prensado de la cera de abeja estaba vinculado sobre todo con algunas áreas rurales de la zona de Terra de Montes, en el interior de la provincia de Pontevedra. De este modo, en esa comarca este oficio vivía un gran apogeo gracias a la existencia de varias infraestructuras específicas de prensado de cera de abeja. Concretamente, Dosiglesias (Forcarei) concentraba seis de los diez lagares de exprimir cera en funcionamiento en la zona. ${ }^{81}$ Sin embargo, la actividad de prensado de cera no era exclusiva de esta área montañosa. En esta misma época, el Catastro de Ensenada nos indica que existían más lagares de cera en otros puntos geográficos. Valga como ejemplo el de Mouriscados, perteneciente al ayuntamiento de Mondariz (Pontevedra), donde había un lagar que servía para «estrujar» la cera.

El prensado de la cera de abeja permitía, como se ha indicado con anterioridad, la obtención de cera purificada en bloque. A partir de este proceso, el producto se podía comercializar directamente, tal como hacían muchos habitantes de Forcarei de las parroquias de Quintillán, del propio núcleo de Forcarei y, fundamentalmente, de la parroquia de Dosiglesias. ${ }^{82} \mathrm{~A}$ mediados del siglo XVIII la mayor parte de los hombres de esta última parroquia se dedicaban al comercio de la cera, concretamente el $56,7 \%$ de los varones de 18 o más años ejercían esta actividad.$^{83} \mathrm{El}$ municipio de Forcarei era, por tanto, un importante foco de actividad cerera, pues contaba en esa época con 31 tratantes de cera. ${ }^{84}$

A mediados del siglo XIX el prensado de cera continuaba siendo una actividad relevante en espacios geográficos como Terra de Montes, tal como nos muestran las referencias del Diccionario de Madoz. Así, esta comarca seguía siendo el lugar de mayor actividad cerera, ejerciendo Forcarei de capital de la industria apícola cerera. Efectivamente, en esta localidad los borreiros $^{85}$ se dedicaban a recoger en la mayor parte de los pueblos de Galicia cera que «acopian, cuecen y prensan, haciendo en ello un mediano lucro». Dentro de For-

80. Lemeunier (2011a), pp. 260-261.

81. Fernández Cortizo (2008), p. 348.

82. Ibid. (2002), p. 254.

83. Ibid. (2008), p. 348.

84. Seijas Montero (2013), p. 58.

85. El término «cerero» y el de borreiro se pueden emplear como sinónimos. Lorenzo Fernández (1995). 
carei las principales actividades cereras estaban localizadas en núcleos rurales. Así, se citan dos parroquias con actividad de prensado y de venta de cera, en concreto Meavía, donde los habitantes se dedicaban a la compra del cerón por los colmenares, para vender posteriormente la cera que extraían de ellos; y Dosiglesias, donde los vecinos asimismo se dedicaban a elaborar cera, comprando en otros puntos la materia prima. En Cerdedo, otro ayuntamiento de la misma comarca, también consta la existencia de actividad cerera, señalándose que los vecinos se dedicaban a recoger por diferentes puntos de Galicia cera, la cual «acopian, cuecen y prensan, por lo que obtienen una mediana ganancia».

La otra gran zona de referencia para actividad apícola cerera en esta época, a tenor de las fuentes consultadas, era el ayuntamiento de O Covelo. En esta localidad, el Diccionario de Miñano nos indica que había en torno a 1825 una fábrica de cera que seguramente se corresponde con la actividad industrial de prensado de cera que señala poco después el Diccionario de Madoz para A Lamosa, lugar que contaba también con operaciones comerciales de extracción de cera ${ }^{86}$ Por otra parte, cabe señalar que el comercio de cera de abeja no se producía exclusivamente en espacios de media montaña de Pontevedra. Así, en áreas de Ourense también se cita el comercio de cera gallega en esa época hacia Castilla y León a principios del siglo XIX, indicando que esta actividad exportadora del producto de la abeja tuvo cierto valor. ${ }^{87}$

Para poder relativizar la relevancia de la industria de prensado de cera en relación con el conjunto de España resulta necesario consultar las estadísticas fiscales. Efectivamente, una circunstancia que nos permite incrementar la información sobre la industria apícola cerera consiste en que estas actividades estaban inseridas en la contribución industrial. ${ }^{88}$ De este modo, una fuente fiscal importante que nos aporta información sobre el objeto de estudio a partir de mediados del siglo XIX es la Estadística Administrativa de la Contribución Industrial y de Comercio. ${ }^{89}$ En el caso concreto que estamos abordando esta fuente aporta información sobre las infraestructuras cereras, prensas y blanqueadores de cera. En efecto, las prensas de cera aparecen como epígrafe propio dentro de esta fuente fiscal, teniendo que tributar, aunque no funcionasen todo el año. ${ }^{90}$ Estas infraestructuras cereras, manuales en un principio, se fueron modernizando, por lo que las modalidades de prensas existentes en la con-

86. El comercio de cera en bruto ya existía en O Covelo a mediados del siglo XVIII, concretamente en Baldomar, tal como consta en el Catastro de Ensenada.

87. Otero Pedrayo (1958), pp. 259-260.

88. Resulta de interés señalar que durante el siglo XIX el esfuerzo fiscal exigido a la industria era menor que al que era sometida la agricultura. Vallejo Pousada (2006), p. 576.

89. Es necesario tener en cuenta que esta fuente fiscal no incluye al País Vasco ni a Navarra.

90. Carrasco (1867), p. 428. 
tribución se fueron ampliando a lo largo de los años, ${ }^{91}$ aunque estos avances tecnológicos no llegaron al rural gallego, que mantuvo las prensas tradicionales hasta la desaparición de esta industria apícola en estos entornos.

La siguiente tabla nos muestra la dinámica numérica de prensas de cera existentes en las provincias gallegas y en España. Así, en los años estudiados, que abarcan desde mediados del siglo XIX hasta 1925, el porcentaje de las prensas de cera gallegas está entre el 9,6\% y el 12,5\%, de las que aparecen en la matrícula de la contribución industrial en el conjunto de regiones contempladas. Los datos cuentan con variaciones considerables en pocos años, lo que genera algunas dudas sobre la fiabilidad. Por ejemplo, resulta llamativo el salto de tres a siete prensas de cera en Ourense en un período de apenas seis años o la desaparición de prensas de cera en Pontevedra en el año 1910, una década en la que, como veremos posteriormente, existen muchas cererías en funcionamiento en esta provincia. En este sentido, dado el carácter fiscal de esta fuente de información, la localización rural y el pequeño tamaño de estas industrias cereras, es razonable pensar que el número de prensas era superior al recogido en la Contribución. Ciertamente, tal como acontece en otras actividades industriales rurales, ${ }^{92}$ la fiabilidad de la información de las fuentes fiscales es relativa, dada la existencia de mercado que no pasaba por los cauces oficiales y, por tanto, no constaba en las fuentes fiscales. Aun así, estas fuentes son relevantes ya que son las únicas que nos permiten conocer la existencia de la actividad y las dinámicas temporales. Teniendo en cuenta esta cuestión señalada, la información que nos aporta esta fuente nos indica que a partir de los años sesenta del siglo XIX se produce una reducción importante

TABLA 2 - Dinámica del número de prensas de cera en Galicia y España (1857-1950)

\begin{tabular}{|c|c|c|c|c|c|c|}
\hline & 1857 & 1863 & 1879 & 1910 & 1925 & 1950 \\
\hline Coruña, A & 4 & 6 & 5 & 5 & 1 & 0 \\
\hline Lugo & 1 & 3 & 0 & 0 & 0 & 0 \\
\hline Ourense & 3 & 7 & 0 & 2 & 2 & 1 \\
\hline Pontevedra & 6 & 5 & 4 & 0 & 3 & 0 \\
\hline Galicia & 14 & 21 & 9 & 7 & 6 & 1 \\
\hline España & 127 & 170 & 93 & 56 & 62 & 73 \\
\hline
\end{tabular}

Fuente: Elaboración propia a partir de la Estadística Administrativa de la Contribución Industrial y de Comercio.

91. En el año 1910 se distingue entre prensas de cera manuales y prensas de cera movidas mecánicamente (por agua, vapor, gas, etc.), pero no existe ninguna referencia a estas últimas en Galicia en los años de estudio. p. 109.

92. Tal como también ocurre para el caso de la industria textil. Álvarez Martín (2013), 
del número de prensas de cera de abeja, por lo que se inicia el declive y posterior desaparición de esta actividad industrial en las áreas rurales de Galicia. Así, en el año 1950 en la Contribución apenas consta una prensa de cera en la provincia de Ourense.

\section{La industria de blanqueo de cera}

El proceso de transformación de cera amarilla a cera blanca aparece también vinculado espacialmente con los espacios rurales. Así, a tenor de la información recopilada y del trabajo de campo realizado, el área geográfica principal de blanqueo de cera en el período de estudio, era el ayuntamiento de O Covelo. Efectivamente, a mediados del siglo XIX el Diccionario de Madoz muestra cómo en este municipio había dos parroquias con dedicación a esta actividad. Concretamente, A Lamosa, donde llegó a haber veinte casas con blanqueador de cera, ${ }^{93}$ y Prado de Canda, donde los habitantes también se dedicaban a blanquear la cera. En esta localidad pontevedresa se produce un interesante proceso de especialización productiva al que se dedicaron importantes esfuerzos, ${ }^{94}$ ya que para esta labor se necesitaban infraestructuras específicas de difícil construcción, los tendales de cera y las pilas de blanqueo, que además eran de carácter permanente e inmóvil. El gasto que suponía poder desarrollar esta actividad se compensaba por la creación de valor añadido en el producto de las abejas y, consecuentemente, la posibilidad de obtener mayores ingresos a partir de la comercialización del producto blanqueado en forma de bloque o de manufacturas.

TABLA 3 - Dinámica del número de blanqueadores de cera en Galicia y España (1879-1950)

\begin{tabular}{lrccc}
\hline & 1879 & 1910 & 1925 & 1950 \\
\hline Coruña, A & 11 & 5 & 2 & 1 \\
\hline Lugo & 5 & 0 & 1 & 1 \\
\hline Ourense & 4 & 0 & 0 & 0 \\
\hline Pontevedra & 0 & 1 & 4 & 0 \\
\hline Galicia & 20 & 6 & 7 & 2 \\
\hline España & 116 & n.d. & 31 & 26 \\
\hline
\end{tabular}

Fuente: Elaboración propia a partir de la Estadística Administrativa de la Contribución Industrial y de Comercio.

93. Sampedro (2007), p. 174.

94. El proceso de innovación tecnológica de las sociedades rurales experimentado en las actividades agrarias ha sido estudiado por Fernández Prieto (1999). 
El blanqueo de cera no era exclusivo de O Covelo. El trabajo de campo realizado indica que existían infraestructuras similares, ya desaparecidas, en otras áreas rurales de los ayuntamientos de Forcarei, Valadouro o Sober, existiendo también referencias a esta actividad en el ayuntamiento de Xunqueira de Ambía. ${ }^{95}$ Por otra parte, la información de la Contribución Industrial, que nos suministra datos sobre los blanqueadores de cera en el territorio gallego y estatal, ${ }^{96}$ muestra la existencia de estas industrias de blanqueo de cera en las cuatro provincias gallegas. Como podemos observar, según esta fuente, en 1879 en Galicia había veinte blanqueadores de cera anexos a las cererías que representaban el 17\% de los que trabajaban en España. Posteriormente, el número de blanqueadores se reduce drásticamente en los años 1910 y 1925, aun-

MAPA 1 - Caracterización geográfica de las principales áreas de prensado, blanqueo y producción de cera en Galicia a mediados del siglo XIX

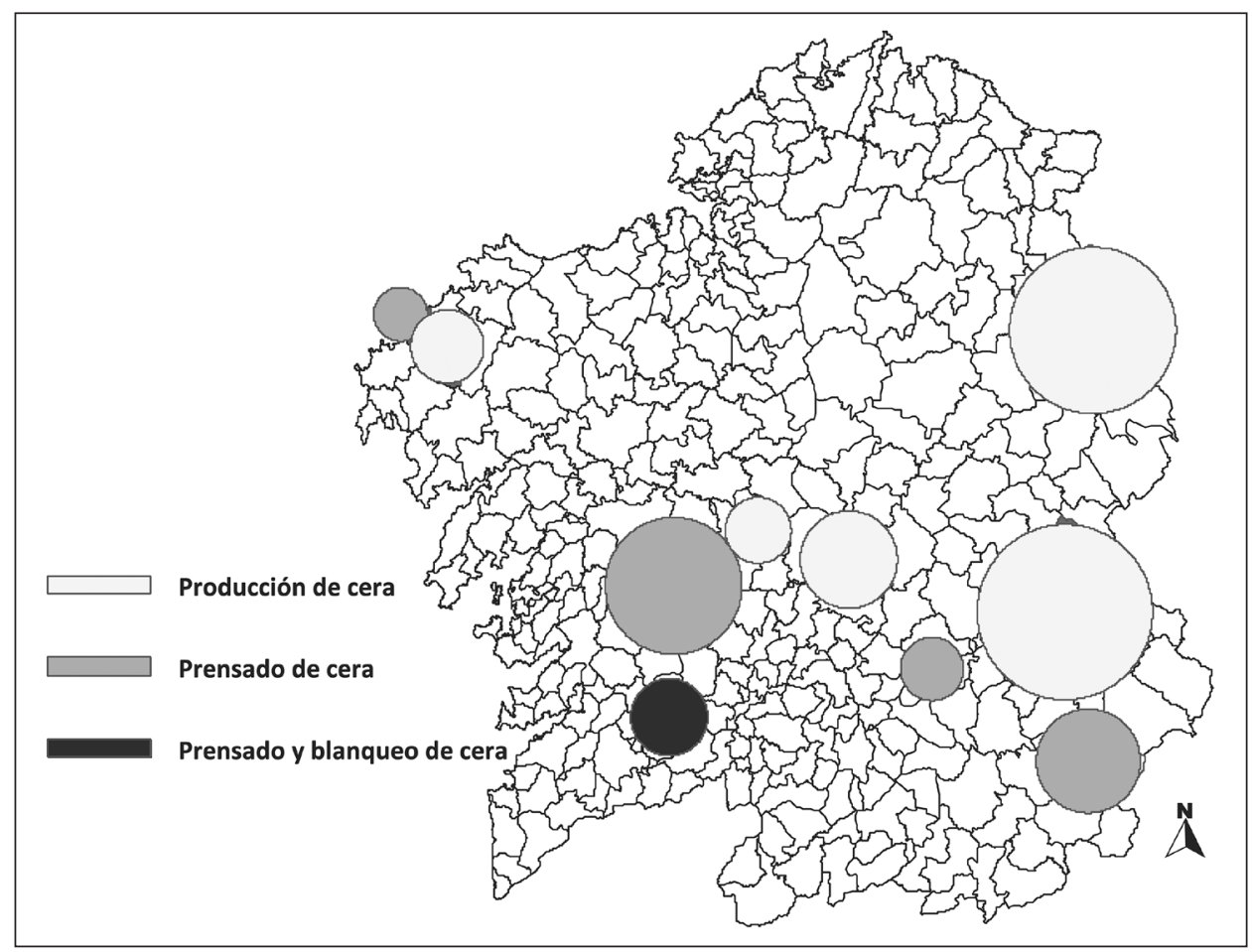

Fuente: Elaboración propia a partir de los diccionarios de Madoz y Miñaño.

95. Soeiro (2011), p. 194.

96. Como en el caso de las prensas, los blanqueadores de cera también tenían que tributar por ejercer esta actividad. En las cuotas se diferencia entre blanqueadores anexos a la cerería o no, contando esta primera opción con una cuota reducida. Revista de los Tribunales (1942). 
que se incrementa la importancia relativa de los gallegos con un $22,6 \%$ en este último año. En el año 1950, ya en pleno declive de la actividad, existían apenas dos blanqueadores en Galicia.

Como hemos comprobado, tanto la obtención de materia prima como la industria de prensado y de blanqueo de cera en Galicia estaban muy ligadas a los espacios rurales ${ }^{97} \mathrm{y}$, principalmente, a algunos municipios pontevedreses cercanos a la Dorsal Gallega de la zona de Terra de Montes y también al ayuntamiento de $\mathrm{O}$ Covelo. Esta distribución espacial la podemos observar en el mapa siguiente, que nos muestra, a partir de la información suministrada por los Diccionarios de Madoz y Miñaño, cuáles eran a mediados del siglo XIX las áreas geográficas más relevantes en las fases de producción, prensado y blanqueo de cera para el territorio de Galicia.

\section{La industria de manufactura de la cera}

El ciclo de procesos de la cerería apícola solía terminar con la manufactura de los bloques de cera amarilla o blanca que se transformaban en el obrador cerero en velas o exvotos. Desde mediados del siglo XVIII aparecen referencias de cereros en diferentes lugares de la geografía gallega, como las ya señaladas que constan en el Catastro del Marqués de la Ensenada en áreas de montaña de Pontevedra o las de Pontedeume. ${ }^{98}$ La existencia de grandes cererías queda acreditada a finales del siglo XVIII en las Memorias Políticas y Económicas sobre los Frutos, Comercio, Fábricas y Minas de España, que indican la existencia de siete cererías en Galicia con un consumo de unas cuatro mil libras de cera, número que se mantiene en el Censo de Frutos y Manufacturas de España e Islas Adyacentes de 1803, donde se señala el mismo número de instalaciones. Posiblemente, dos de estas cererías sean las fábricas que citan en los contornos de la ciudad de Lugo que trabajaban al año de seis a siete mil libras de cera, ${ }^{99}$ aproximadamente unas tres toneladas. ${ }^{100}$ Otros lugares, como la zona de Terra de Montes, que, como ya hemos comprobado, era un gran epicentro apícola cerero, también contaban a mediados del siglo XIX con cererías como la «fábrica abundante de velas de cera» que se localizaba en Forcarei, en el lugar de Acebeiro. ${ }^{101}$

Como ocurre para el prensado y el blanqueo de la cera, la estadística de la Contribución Industrial también nos aporta alguna información de utilidad

97. El noroeste peninsular contaba con otras industrias de ámbito rural como la vinculada con la producción de tejidos de lino, analizada por Carmona Abadía (1984) o la del corcho que nos muestra Guerra Velasco (2015).

98. Daviña Sáinz (2001), pp. 128-129.

99. Lucas Labrada (1804).

100. Lemeunier (2011a), p. 264.

101. Miñano (1829). 
sobre las cererías existentes en el territorio gallego. Concretamente, en 1910 había siete contribuyentes con siete pailas en la provincia de A Coruña y una en Pontevedra. En 1925 se produce un importante incremento con un total de veintisiete contribuyentes. De ellos, veintidós con paila y cinco cererías con noque. De estas cererías, la mayor parte estaban localizadas en las provincias de Pontevedra y A Coruña, los espacios con más población y más demanda de cera de abeja. El número de cererías que nos muestra la Contribución Industrial contrasta con la información que nos suministra otra fuente histórica de interés. Efectivamente, el Anuario General de España y su antecedente, el Anuario Bailly-Bailliere, nos indican que las cererías eran mucho más abundantes en Galicia. ${ }^{102}$ Así, utilizando los datos del año 1886 y de 1913 podemos tener una idea global del nivel de implantación de la actividad manufacturera cerera y de la distribución geográfica de estas industrias de fabricación de velas de cera de abeja y otros productos en el territorio gallego, tal como se recoge en el mapa 2. De este modo, en el año 1886, según la fuente indicada, había en Galicia un total de noventa y nueve cererías, localizándose casi la mitad de ellas en la provincia de Pontevedra. En el año 1913 la cifra de cererías es todavía más espectacular con un total de ciento treinta y cuatro, de las que cincuenta y dos estaban en la provincia de A Coruña y cuarenta y siete en la de Pontevedra. En los dos años considerados, resulta significativo constatar cómo de las cererías que aparecen en los Anuarios, la mayor parte estaban localizadas en áreas rurales. Solo en la provincia coruñesa existen varias cererías en los entornos más urbanos, como por ejemplo las nueve de Santiago de Compostela o las seis de A Coruña en 1913. Sin embargo, las áreas y los lugares concretos con mayor número de cererías son, de manera coincidente con la información histórica señalada anteriormente, Terra de Montes ${ }^{103}$ y el ayuntamiento de O Covelo. De este modo, en 1886 había once cererías en Terra de Montes, que se mantienen en diez en el Anuario de 1913. Estas cererías estaban localizadas principalmente en Forcarei, pero no solo en el núcleo principal del ayuntamiento, sino también en lugares ya conocidos como Dosiglesias, Acebeiro o Quintillán. No obstante, sin lugar a dudas, el dato más espectacular es el relativo al ayuntamiento de O Covelo, con dieciocho cererías en 1886 y dieciséis en 1913. Destaca el hecho de que estas cererías se encuentran mayoritariamente en una misma parroquia, la de A Lamosa. El número de cererías que se situaban en esta parroquia es de catorce

102. Tal como acontece con las prensas de cera, la gran diferencia en el número de cererías que se constata entre las fuentes fiscales y los Anuarios nos indica la posible ocultación de información. En este sentido, la localización rural y el pequeño tamaño de las cererías rurales, explica el escaso número que aparece recogido dentro de la Contribución Industrial.

103. Considerando también al ayuntamiento de A Estrada, con cererías en las aldeas de Orazo, Nigot y Olives. 
en $1886^{104}$ y de trece en 1913. En esta localidad el análisis de los titulares de las cererías muestra cómo se repiten varios apellidos como Lamela, Lamosa y Mariño, lo que denota que el oficio cerero se extendía a través de los entornos familiares. También existen otros ejemplos singulares de concentración de cererías en espacios rurales en el año 1886 como las cuatro cererías del lugar de Paradela, ayuntamiento de Meis (Pontevedra) o las tres de Cartelle en la provincia de Ourense. Estas pequeñas cererías radicadas en municipios rurales cercanos a áreas de media montaña con importancia apícola trataban en ocasiones de cerrar completamente el ciclo de la cera. Así, se hacían acopio de la materia prima, su prensado y, en espacios concretos como A Lamosa, se desarrollaba el blanqueo de este producto de las abejas, llegando, finalmente, a su manufactura y venta final. Un análisis de las cererías existentes en estas pequeñas aldeas rurales nos demuestra la existencia de posibles vinculaciones familiares entre ellas. Ciertamente, se puede concluir que la cerería apícola rural estaba muy vinculada con el trabajo familiar y que pretendía maximizar la autogestión de las fases del proceso productivo. Este es, probablemente, uno de los motivos que explica la concentración de la industria cerera en pocas comarcas rurales de Galicia. Por otra parte, una vez iniciada esta actividad industrial cerera, se pueden abarcar los diferentes procesos vinculados creando sinergias evidentes y economías de escala. Evidentemente, si existe un centro de prensado, la materia prima necesaria para el blanqueo y la transformación manufacturera están aseguradas. Por último, la cuestión geográfica es importante. Comarcas como Terra de Montes y A Paradanta son lugares con altas concentraciones de colmenas, vinculados con la Dorsal Gallega y que se encuentran bien localizados para trasladarse a otras áreas de media montaña que cuentan con importancia apícola.

Los mapas que aparecen a continuación nos muestran la distribución geográfica de las cererías gallegas y su importancia numérica por ayuntamiento en los años 1886 y 1913. Como se puede observar, los espacios del interior gallego concentran una parte importante de las cererías existentes, cuestión esta que sucede de manera destacada en las áreas geográficas que conforman la denominada Dorsal Gallega. Estos lugares de media montaña contaban con grandes extensiones de matorral, en los que predominaban las ericáceas y otros arbustos de interés apícola, muy propicios para el desarrollo de la apicultura, lo que favorecía la obtención de la materia prima para la industria cerera apícola tradicional.

104. Para hacernos una idea de la importancia de esta actividad en A Lamosa, basta señalar que el Diccionario de Madoz nos indica que a mediados del siglo XIX en este lugar existían ciento catorce casas, lo que le confiere mayor significancia relativa a las catorce cererías que constan en el Anuario de 1886. 
MAPA 2 - Caracterización geográfica de las cererías en Galicia (1886 y 1913). Número de cererías

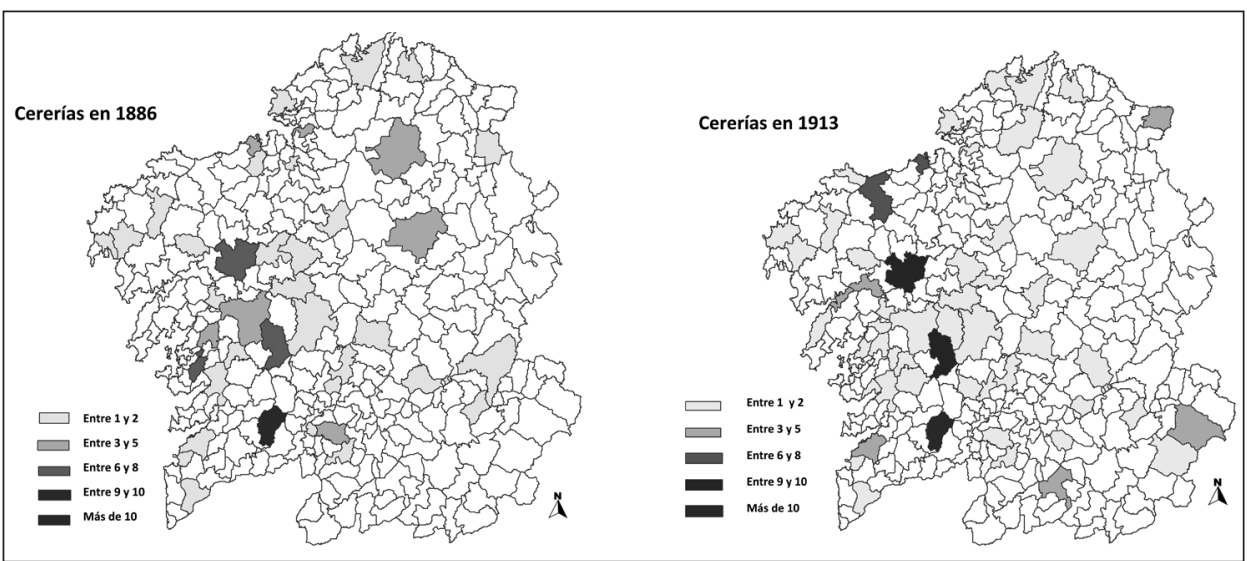

Fuente: Elaboración propia a partir de los datos del Anuario Bailly-Bailliere de 1886 y del Anuario General de España de 1913.

Los elementos vinculados con los procesos de prensado y de blanqueo de cera, específicos de la industria apícola cerera, dejaron de funcionar a mediados del siglo pasado, aunque alguna infraestructura continuó alguna década más en activo. ${ }^{105}$ La sustitución de insumos en el proceso productivo, debido al abaratamiento y la garantía de suministro de los productos alternativos y a la menor demanda eclesiástica, unida a la modernización de la industria de la iluminación, supuso la pérdida de la utilidad de estas infraestructuras específicas y el abandono progresivo de las mismas hasta su desaparición definitiva. El uso de parafina en la producción de velas, con la consecuente disminución de la demanda de la cera de abeja, provocó el abandono paulatino de la actividad. Ciertamente, las pequeñas industrias tradicionales de prensado y blanqueo de cera de abeja, localizadas en las áreas de interior de Galicia, como las de Covelo y Forcarei, no pudieron, o no supieron, adaptarse al cambio de tiempos. ${ }^{106}$ No obstante, los obradores tradicionales cereros existentes en los espacios rurales de Galicia sí que trabajaron durante algunas décadas con el cambio de insumos en el proceso de elaboración de manufactu-

105. Como el lagar de cera de Casanova en Forcarei propiedad de la familia Espiña. Fuentes Allende (1994).

106. Un ejemplo singular de adaptación y supervivencia de esta actividad en espacios rurales lo podemos encontrar cerca de Galicia, en el lugar de Sagallos (Manzanal de Arriba, en Zamora), donde una cerería tradicional con lagar de cera de prensa de viga, propiedad de la familia Romero, mantiene la actividad de prensado de cera de abeja utilizando las nuevas tecnologías de prensado hidráulico y destinando su producción a nichos de mercado como las láminas de cera para apicultura. 
ras. Así, mantuvieron unas décadas la actividad, aunque con escasa presencia de cera de abeja. Es la paradoja de que se habla de artesanía de la cera y, sin embargo, este producto apenas se utiliza en el trabajo de la cerería. ${ }^{107}$ La cerería sin cera de abeja ${ }^{108}$ es la realidad de las últimas décadas, destinándose generalmente el producto apícola a nuevos usos que nada tienen que ver con la producción de velas.

La importancia que tuvo la industria apícola cerera en las áreas rurales ha dejado como legado un vasto patrimonio material e inmaterial específico, tal como hemos señalado en el apartado de procesos y elementos. Esta riqueza patrimonial, que es necesario conservar, puede convertirse en un importante elemento dinamizador del turismo y de la economía de espacios rurales deprimidos socioeconómicamente. ${ }^{109}$ En este sentido, cabe señalar la existencia de una interesante iniciativa desarrollada por una entidad comunitaria gallega, la Comunidade de Montes Veciñais en Man Común de Paraños (O Covelo). Esta comunidad ha creado el Centro de Interpretación de la Cerería de Paraños, rehabilitado el lagar de cera de prensa de viga de este lugar y señalizado e incluido dentro de una ruta de senderismo otros elementos de la cerería apícola como las eiras de cera. Con este proceso la entidad vecinal trata de fomentar la dinamización económica de este espacio geográfico y el mantenimiento del patrimonio y de la memoria de la cerería apícola del municipio. ${ }^{110}$

\section{Conclusiones}

El trabajo de investigación realizado constata la relevancia de la actividad apícola cerera en determinados espacios rurales del territorio gallego en el período analizado en las diferentes fases del ciclo productivo de la cerería apícola. La industria cerera estaba vinculada directamente con las colmenas fijistas que producían miel y cera, contando este último producto con un valor de cambio y de mercado que percibían los pequeños apicultores. Gracias a esta actividad orgánica la industria apícola cerera gallega se desarrolló en diferentes espacios geográficos vinculados con el mundo rural. En municipios como Forcarei en Terra de Montes o el de O Covelo en A Paradanta la apicultura cerera registró una gran importancia, por lo que existen numerosas

107. Como ejemplo cabe indicar que en las velas las denominaciones máxima y notábile indican composiciones de un $60 \%$ y un $30 \%$ de cera de abejas, respectivamente. Garmendia Larrañaga (1970).

108. Díaz Maderuelo et al. (1985).

109. Simón Fernández y Prado Orbán (2006).

110. Copena et al. (2016) 
referencias históricas sobre esta actividad desde mediados del siglo XVIII hasta mediados del XX. Estas industrias cereras rurales trataban en ocasiones de abarcar todos los ámbitos de la actividad cerera, desde la obtención de la materia prima, pasando por el prensado del producto para el posterior blanqueo de la cera e incluso llegaban a manufacturar y vender los productos finales elaborados a partir de la cera de abeja, en especial velas y exvotos. La cerería apícola gallega, que tenía una relevancia significativa dentro del ámbito español, contaba con procesos y elementos específicos. Así, tras la adquisición de la materia prima para el proceso productivo, los restos de las colmenas se prensaban en los lagares de cera para conseguir bloques de cera amarilla que vender o manufacturar con posterioridad. La cera amarilla se podía transformar en blanca a partir de un proceso natural que se aprovechaba de la acción solar. La actividad de blanqueo de la cera le dotaba de valor añadido al producto apícola. Finalmente, la cera de abeja, amarilla o blanca se manufacturaba en los obradores cereros que se dedicaban a la fabricación de velas y exvotos.

El trabajo de investigación realizado constata cómo la actividad apícola cerera estaba muy vinculada con los espacios rurales, sobre todo en lo relativo a los procesos de prensado y blanqueo de la cera, aunque también la manufactura final. Esta industria rural necesitaba de infraestructuras específicas tanto para el prensado como para el blanqueo, como los lagares de cera y los tendales de cera o pilas de blanqueo. Del mismo modo, en el proceso de manufacturado también existían piezas específicas como la rueda cerera o la paila. Solo estas últimas, al contrario que las infraestructuras de prensado y blanqueo, pudieron subsistir momentáneamente al cambio de materia prima.

La actividad industrial cerera fue perdiendo, de manera progresiva, la vinculación con la apicultura. La generalización del uso de otros insumos, como la estearina y sobre todo la parafina, que sustituían a la cera de abeja en el proceso productivo, provocó la desaparición de la industria apícola cerera en el rural gallego. Aun así, el importante desarrollo que alcanzó la actividad apícola cerera gallega en determinados espacios rurales ha propiciado la existencia, a día de hoy, de relevantes ejemplos de patrimonio específico de esta industria. Ciertamente, en la actualidad, como acredita el trabajo de campo realizado, existen interesantes elementos patrimoniales repartidos por diferentes espacios rurales del territorio gallego. Los lagares de cera de prensa de viga o los tendales para el blanqueo que podemos encontrar en Galicia son unos de los pocos ejemplos en pie de estas infraestructuras en la península ibérica. La aparición de estas infraestructuras indica la necesidad de continuar con la búsqueda de nuevos elementos patrimoniales y asegurar la conservación y la puesta en valor de los existentes, tal como ya se está haciendo por iniciativa de una entidad comunitaria en O Covelo. 
Los resultados de este trabajo de investigación aportan información sobre una actividad ligada a la cera de abeja sobre la que existe gran desconocimiento y escasa investigación científica. Este hecho resulta más relevante si tenemos en cuenta que en Galicia algunos procesos de la cerería apícola se desarrollaron principalmente en espacios rurales. Resulta pues necesaria la realización de nuevas investigaciones específicas sobre la industria apícola cerera en otros espacios de la geografía ibérica. El estudio de las dinámicas históricas y el análisis de la tecnología usada en esta actividad es una necesidad imperiosa, dada la inminente pérdida de patrimonio material e inmaterial vinculado con este oficio en su variante apícola. Estas investigaciones permitirían poder incrementar el conocimiento sobre la relevancia y alcance de esta actividad y posibilitar el llevar a cabo análisis comparativos entre espacios geográficos. Del mismo modo, sería conveniente la realización de trabajo de campo específico para identificar infraestructuras específicas de esta actividad apícola tradicional, en especial los lagares de prensado de cera y los blanqueadores de cera, dada la singularidad con la que cuentan estos elementos específicos de la industria vinculada con la cera de abejas.

\section{BIBLIOGRAFÍA}

Alonso GonzÁlez, J. M. (1987). «Lagares de cera: un primitivo sistema de elaboración industrial». Anuario del Instituto de Estudios Zamoranos Florián de Campos, n. ${ }^{\circ}$, pp. 233-241.

Álvarez Martín, M. M. (2013). «La decadencia de la industria textil en Castilla y León y el espejismo de la autarquía franquista (1898-1952)». Investigaciones de Historia Económica, n. ${ }^{\circ}$ 9, pp. 108-119.

Argente Oliver, J. L.; Lafuente Izquierdo, A.; Colín Vinuesa, C. (1992). La cerería: producción artesanal en la provincia de Soria. Soria: Junta de Castilla y León.

ArmendÁRiz Martija, J. (1998). «La cerería en Puente la Reina (Navarra), 1870-1950». Cuadernos de etnología y etnografía de Navarra, n. ${ }^{\circ}$ 71, pp. 59-104.

Bas, B. (1983). As construcións populares. Un tema de etnografía en Galicia. Sada: Do Castro.

Bellido Blanco, A. (2006). Catálogo temático de los fondos etnográficos, Museo Numantino. Valladolid: Consejería de Cultura y Turismo.

CAAmaño SuÁrez, M. (2003). As Construcións da arquitectura popular: patrimonio etnográfico de Galicia. Santiago de Compostela: Consello Galego de Colexios de Aparelladores e Arquitectos Técnicos.

CARmona Abadía, X. (1984). «Clases sociales, estructuras agrarias e industria rural doméstica en la Galicia del siglo XVIII». Revista de Historia Económica - Journal of Iberian and Latin American Economic History, n. ${ }^{\circ}$ 3, pp. 35-50. 
Cassell, C.; Symon, G. (2004). Essential Guide to Qualitative Methods in Organizational Research. Londres: Sage Publications.

Castellote Herrero, E. (1988). Cera y cerería en Guadalajara. Revista de dialectología $y$ tradiciones populares, . $^{\circ} 43$, pp. 133-149.

Cendón González, A.; Copena Rodríguez, D.; Copena Rodríguez, D. (2011). Favum, o lugar da cera. Covelo: CMVMC de Paraños.

Clément, H. (2012). Tratado de Apicultura. Barcelona: Omega.

Consellería de Presidencia, Administracións Públicas e Xustiza. (2008). Decreto 170/2008, do 17 de julio, por el que se aprueba el escudo del Ayuntamiento de Forcarei (Pontevedra). Diario Oficial de Galicia, n. ${ }^{\circ}$ 159, p. 15724.

Copena Rodríguez, D.; Copena Rodríguez, D.; Simón Fernández, X. (2016). «A posta en valor do patrimonio apícola cereiro tradicional: análisis da experiencia comunitaria da CMVMC de Paraños». La Descomunal. Revista Iberoamericana de Patrimonio y Comunidad, n. ${ }^{\circ} 2$, pp. 237-248.

CRuz García, O. (1989). Descubrimiento del pasado artesanal de la subcomarca de la Carballeda. Revista de Folklore. Fundación Joaquín Díaz, n. ${ }^{\circ}$ 97, pp. 3-11.

Daviña Sáinz, S. (2001). Pontedeume a través del Catastro de Ensenada. Cátedra: Revista Eumesa de Estudios, n. ${ }^{\circ}$ 8, pp. 113-157.

Díaz Maderuelo, R.; Zapata de la Vega, J.; Adánez Pavón, J.; Quinto Romero, M. L. (1985). El oficio artesano de cerería en Segovia. Etnografía española, n. ${ }^{\circ}$ 5, pp. $273-$ 351.

Fernández Cortizo, C. (2002). La Tierra de Montes en la Época Moderna. Permanencias y cambios en una sociedad rural del Antiguo Régimen. Obradoiro de Historia Moderna, n. ${ }^{\circ} 11$, pp. 247-288.

- (2008). Arrieros y traficantes en la Galicia rural de la época moderna. Obradoiro de Historia Moderna, n. ${ }^{\circ}$ 17, pp. 325-352.

FERnÁndez Prieto, L. (1999). Estado, sociedad rural e innovación tecnológica en la agricultura. Los cambios en torno a 1900. Studia historica. Historia contemporánea, n. ${ }^{\circ} 17$, pp. $67-103$.

Fuentes Allende, X. (1994). Exvotos de cera: tecnoloxía e funcionalidade en Tecnoloxía Tradicional: Dimensión Patrimonial e valoración Antropolóxica. En Actas do Simposio Internacional In Memoriam Xaquín Lorenzo, pp. 227-260. Consello da Cultura Gallega, Ourense.

Garmendia Larrañaga, J. (1970). Artesanía vasca. Donostia: Eusko Ikaskuntxa.

Gillham, B. (2000). Case Study Research Methods. Londres: Continuum.

GonzÁlez PÉrez, C. (1989). Apicultura tradicional no concello de Navia de Suarna (Lugo). Lugo: Deputación Provincial.

Guerra Velasco, J. C. (2015). La industria corcho-taponera en el noroeste de España: origen y evolución de una actividad de perfil artesanal (1827-1977). Revista de historia industrial, n. ${ }^{\circ} 57$, pp. 55-86. 
Ledo GonZÁlez, B. (1925). La apicultura en Galicia llegaría a ser un artículo de primer orden, cultivada por procedimientos modernos. Primer Congreso de Economía Gallega, pp. 107-111. Lugo: La Voz de la Verdad.

- (1929). Cursillo práctico de apicultura adaptado a la región gallega. Lugo: Imprenta Provincial.

Lemeunier, G. (2011a). Geografía de la cera en España y Francia, 1750-1850. Investigaciones de Historia Económica, n. ${ }^{\circ}$ 7, pp. 259-269.

- (2011b). La apicultura en Francia y España entre los siglos XVIII y XIX. Historia Agraria, n. ${ }^{\circ} 54$, pp. $17-40$.

LÓPEz Álvarez, X. (1994). Las abejas, la miel y la cera en la sociedad tradicional asturiana. Oviedo: Real Instituto de Estudios Asturianos.

Lorenzo Fernández, X. (1995). Os oficios. Vigo: Galaxia.

Magrama. (2016). Programa Nacional de medidas de ayuda a la apicultura. España 20172019. Madrid: Ministerio de Agricultura, Alimentación y Medio Ambiente.

Otero Pedrayo, R. (1958). Exportación de cera de orense a fines del XVIII y comienzos del XIX. Cuadernos de Estudios Gallegos, n. ${ }^{\circ} 40$, pp. 259-260.

- (1979). Historia de Galiza II. Madrid: Akal.

REVISTA DE LOS TRIBUNALES. (1942). Contribución industrial. Tarifas y Nomenclator. Madrid: Góngora.

Roma FÁbrega, A. (1982). Apicultura. Hospitalet: Sintes.

SAAVEdRa Fernández, P. (2007). Las comunidades campesinas en la Galicia moderna. En Rodríguez, Ana (ed.). El lugar del campesino: en torno a la obra de Reyna Pastor. Valencia: Universidad de Valencia, pp. 359-390.

Sampedro Fernández, A. (2007). A ceraría no Condado- A Paradanta. Soberosum, n. ${ }^{\circ}$, pp. 165-189.

SAntos Junior, J. R. (1983). Lagar comunitario da cera, Felgueiras, Moncorvo. Trabalhos de Antropologia e Etnologia da Sociedade Portuguesa de Antropologia e Etnologia, vol. 24, n. ${ }^{\circ}$, pp. 489-509.

Seijas Montero, M. (2013). La influencia social de los cisterciense del sudoeste gallego en la edad moderna. Revista de Historia Moderna, n. ${ }^{\circ}$ 31, pp. 55-72.

Simón Fernández, X.; Prado Orbán, X. (2006). Cultura Tradicional e Desenvolvemento Rural. Vigo: Xunta de Galicia e Universidade de Vigo.

Soeiro, T. (2011). A propósito de um lagar de cera e da actividade dos cerieiros em Penafiel. Portvgalia, Nova Série, n. ${ }^{\circ}$ 31-32, pp. 183-213.

Vallejo Pousada, R. (2006). Fiscalidad y agricultura en las Edades Media, Moderna y Contemporánea: síntesis y balance. Historia Agraria, n. ${ }^{\circ}$ 40, pp. 561-596. 


\section{Fuentes estadísticas y tratados históricos}

Abarca Castellano, P. (1835). Manual de colmeneros. Madrid: Imprenta de D. Eusebio Aguado.

Agustín Carrasco, P. (1867). Tratado de las contribuciones directas de España. Madrid: T. Fortanet.

Bailly-BAilliere. (1886). Anuario del Comercio, de la Industria, de la Magistratura y de la Administración. Madrid: Carlos Bailly-Bailliere.

Bailly-Bailliere y Riera. (1913). Anuario general de España. Anuarios Bailly-Bailliere y Riera reunidos. Barcelona: Anuarios Bailly-Bailliere y Riera reunidos.

Catastro de Ensenada. Respuestas Generales del Catastro del Marqués de la Ensenada. 1750-1754.

Collantes, D. M. (1864). Manual del fabricante de velas de sebo, bujías de cera y esteáricas. París: Librería de Ch. Bouret.

Dirección General de Contribuciones. (1856-1927). Estadística Administrativa de la Contribución Industrial y de Comercio. Imp. de Luis García. Madrid.

Dirección General de CONTRiBuciones y RÉGIMEN de EMPRESAS. (1940-1950). Estadística Administrativa de la Contribución Industrial, de Comercio y Profesiones. Madrid: Sobrinos de la Sucesora de M. Minuesa de los Ríos.

Dirección General de Rentas Públicas. (1928-1933). Estadística Administrativa de la Contribución Industrial, de Comercio y Profesiones. Madrid: Sobrinos de la Sucesora de M. Minuesa de los Ríos.

Duhame, du M. (1777). Arte de cerero. Escrito en francés y aumentado con varias notas. Traducido por orden de la Junta General de Comercio, Moneda, y Minas. Madrid: Imprenta de D. Pedro Marín.

Instituto Nacional de Estadística. [Varios años] Anuario de Estadística de España. Madrid.

Junta Directiva del Concurso. (1859-1861). Memoria sobre los productos de la agricultura española reunidos en la Exposición General de 1857. Madrid: Imprenta Nacional.

Labrada, J. L. (1804). Descripción Económica del Reyno de Galicia por la Junta de Gobierno del Real Consulado de la Coruña. Ferrol: Imp. de Lorenzo José Riesgo Montero.

Larruga, E. (1798). Memorias Políticas y Económicas sobre los Frutos, Comercio, Fábricas y Minas de España (vol. XVII). Madrid: Imprenta de Benito Cano.

Madoz, P. (1845-1850). Diccionario geográfico-estadístico-histórico de España y sus posesiones de Ultramar. Madrid: Imp. del Diccionario.

Ministerio de Gracia y Justicia. (1889). Real Decreto de 24 de julio de 1889 por el que se publica el Código Civil. BOE núm. 206, de 25 de julio de 1889.

Miñano y Bedoya, S. (1826-1829). Diccionario Geográfico Estadístico de España y Portugal. Madrid: Imprenta de Pierart-Peralta. 
Pimentel Méndez, R. (1893). Manual de apicultura escrito expresamente para los apicultores gallegos. Vigo: Establecimiento Tipográfico Faro de Vigo.

Polo y Catalina, J. (1803). Censo de Frutos y Manufacturas de España e Islas Adyacentes. Madrid: Imprenta Real.

ReDOndo, I. (1876). Apicultura ó tratado de las abejas y sus labores. Madrid: Quirós.

Ronquillo y Vidal, J. O. (1853). Diccionario de materia mercantil, industrial y agrícola que contiene la indicación, la descripción y los usos de todas las mercancías (vol. II). Barcelona: Impr. de D. A. Gaspar.

Ruiz De la Escalera, E. (1835). Práctica fija de colmeneros ó sea modo único de cuidar las abejas y demostración de la utilidad que rinden. Madrid: Imprenta de D. Miguel de Burgos. 


\section{The beekeeping and beeswax industry in rural Galicia (1750-1950)}

ABSTRACT

This paper aims to contribute to our knowledge of the beeswax industry through the historical study of this economic activity in the territory of Galicia during a historical period that covers from the mid-eighteenth century to the mid-twentieth century. The article notes the relevance of the Galician beekeeping and beeswax industry in certain rural areas of Galicia. We have been able to characterize the different stages of this trade linked with bees, and the main specific heritage elements associated with the beeswax industry, wax presses and threshing floors. The paper allows us to conclude that the beeswax industry was a very important activity in places like Forcarei and Covelo, where it is still possible to find specific heritage related to the pressing and bleaching of beeswax.

KEYwORDS: beeswax industry, rural industry, beeswax, Galicia

JEL CODES: N53, N54, L69, O14

\section{La industria apícola cerera en el rural de Galicia (1750-1950)}

\section{RESUMEN}

El presente trabajo tiene como objetivo contribuir al conocimiento de la industria apícola cerera a partir del estudio histórico de esta actividad económica en el territorio gallego, en un período que abarca desde mediados del siglo XVIII hasta mediados del siglo XX. El artículo permite constatar la relevancia de esta industria ligada a la cera de abeja en determinados espacios geográficos del rural de Galicia. El estudio realizado posibilita la caracterización de las diferentes fases de este oficio vinculado con las abejas, así como los principales elementos patrimoniales específicos vinculados con la industria cerera, los lagares y los tendales de cera. El trabajo concluye que la cerería apícola fue una actividad relevante en lugares como Forcarei o Covelo, donde aún resulta posible encontrar patrimonio específico del prensado o el blanqueo de la cera de abeja.

PALABRAS ClAVE: industria cerera, industria rural, cera de abeja, Galicia.

Códigos JEL: N53, N54, L69, O14 